\title{
ASPECTOS DA SINTAXE DE ADVÉRBIOS CELERATIVOSE DE SUA INTERPRETAÇÃO EM FORMA LÓGICA
}

Tércio Campos Polli

\section{Introdução}

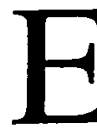

ste artigo, desenvolvido dentro do quadro teórico da Gramática Gerativa, precisamente a partir do modelo de Gramática Universal proposto pela Teoria dos Princípios e Parâmetros, apresenta uma reflexão sobre a interpretação de advérbios celerativos em Forma Lógica, módulo da Faculdade da Linguagem, conforme esta teoria, responsável pela interpretação semântica da estrutura de superfície de sentenças.

Como objetivo, este trabalho tenta descrever gramatical e estruturalmente o fator que possibilita aos advérbios celerativos (aqueles que expressam celeridade, velocidade, tais como rapidamente, velozmente, imediatamente, vagarosamente, lentamente etc.) distribuírem ou não sua predicação sobre even-

* Pós-graduação - Universidade de São Paulo. 
POLLI, T. C. Aspectos da sintaxe de advérbios...

tos de VP, conforme a posição em que aparecem na sentença. Este fato linguiístico é exemplificado nas sentenças abaixo:

(01) a) Rapidamente os alunos saíram do prédio.
b) Os alunos rapidamente saíram do prédio.

Nas sentenças (01 a e b), o advérbio nas posições inicial e auxiliar não consegue distribuir sobre eventos, e a interpretação das sentenças é equivalente a " um grupo $x$ de pessoas saiu do prédio de forma $w$ ", ou seja, o evento é interpretado coletivamente. Podemos, então, entender que o espaço de tempo transcorrido entre o momento em que os alunos estavam dentro do prédio e o momento em que os alunos se encontram fora do prédio não foi longo. O contrário parece ocorrer com as sentenças abaixo:

(02) a) Os alunos saíram rapidamente do prédio.

b) Os alunos saíram do prédio rapidamente.

Nas sentenças ( 02 a e b), com o advérbio em posições pós-verbais, a interpretação do evento de sair é entendida de forma individual, significando que " cada aluno $x$ saiu do prédio de uma mesma forma $w$ ", ou seja, esse tipo de advérbio, nessas posições, consegue distribuir sua predicação sobre os eventos de VP, comportando-se semelhantemente a um sintagma quantificado distributivo-universal.

Este artigo está organizado da seguinte forma: na seção $l$ introduzimos as propostas teóricas de L. Beghelli, T. Stowell e de J. Costa, sendo que a proposta dos dois primeiros refere-se à interpretação de sintagmas quantificados em Forma Lógica; já a do terceiro apresenta argumentos contra a universalidade das categorias funcionais e contra a hipótese de os advérbios serem especificadores. Na seção 2 aplicamos as respectivas teorias (e também alguns argumentos favoráveis de outros autores) a sentenças do português brasileiro com os advérbios celerativos em -mente. Na seção 3 expomos nossas conclusões sobre as propriedades desses advérbios e sobre o processo sintático disponível para manifestá-las. Na seção 6 (última seção) relacionamos as referências bibliográficas. 
POLLI, T. C. Aspectos da sintaxe de advérbios...

\section{Proposta teórica}

\section{A Teoria de Beghelli e Stowell $(1995,1997)$ sobre a interpretação de sintagmas quantificados}

\section{Introdução}

A interpretação associada a sentenças contendo Sintagmas Quantificados $(\mathrm{QPs})^{1}$ tem sido derivada a partir de mecanismos que possibilitam o $\mathrm{QP}$ ter escopo sobre um outro QP na sentença, ou seja, a interpretação de um QP depende da interpretação de outro.

Algumas propostas diferentes já foram feitas na literatura da Gramática Gerativa para implementar tais mecanismos. Uma delas é a dos autores em estudo nesta subseção, ou seja, The Target Landing Site Theory of Scope. A seguir, apresentaremos de forma sintética os principais tópicos de sua teoria.

\section{Alguns tópicos sobre a teoria proposta por Beghelli (1995) e por Beghelli e Stowell (1997)}

A teoria de Beghelli e de Beghelli e Stowell representa um avanço para os estudos concernentes à interpretação de sintagmas quantificados. Apesar de compartilhar com outras teorias já propostas, a hipótese de que o escopo de um QP é atribuído por meio de seu movimento em Forma Lógica (LF) para uma posição da qual ele possa c-comandar o domínio sobre o qual tem escopo, os autores apresentam um novo fator, decisivo para a explicação das possíveis

1 Seguindo a tradição, neste artigo as siglas são introduzidas entre parênteses logo após a primeira aparição de sua forma desenvolvida. A partir de então, apenas aquelas serão usadas ao longo de todo o texto. Optamos, também por usar as siglas correspondentes às expressões em inglês quando estas representarem nomenclaturas utilizadas pela gramática gerativa. 
POLLI, T. C. Aspectos da sintaxe de advérbios...

interpretações geradas por esse processo: o reconhecimento de que diferentes QPs têm diferentes propriedades de escopo. A partir disso, os autores propõem uma tipologia de QPs baseada nessas diferenças e desenvolvem sua teoria de escopo de quantificadores.

A seguir, apresentamos a tipologia de sintagmas quantificados proposta pelos autores:

1. Interrogativos (WhQPs): what, which man etc. Todos possuem um traço $[+\mathrm{WH})$;

2. Negativos (NQPs): nobody, no man etc. Todos possuem um traço $[+\mathrm{Neg})$;

3. Distributivos-Universais (DQPs): every e each, ambos geralmente interpretados como universais e distributivos. Ao DQP each os autores atribuem o traço [Dist(ributivo)] e deixam o every subespecificado para [Dist] e especificado simplesmente para universalidade [+Univ];

4. Contáveis (CQPs): QPs decrescentes com determinantes como few, fewer than five, at most six etc.; e geralmente expressões cardinais com numerais modificados como more than five, between six and nine etc. A propriedade semântica característica destes QPs é que eles contam indivíduos com uma dada propriedade, têm escopo local (geralmente in situ) e resistem a interpretações específicas.

5. Denotadores de Grupo (GQPs): QPs indefinidos como one student, three students etc.; e QPs definidos como the students. Sua propriedade fundamental é a denotação de grupos, incluindo indivíduos plurais. Possuem também a capacidade de introduzir referentes grupais e, consequientemente, a capacidade de atribuir escopo largo.

Exposta a tipologia de sintagmas quantificados proposta pelos autores, interessa-nos, agora, descrever as posições que esses constituintes podem ocupar em LF para produzir diferentes interpretações. A idéia básica dos autores é que existe na periferia esquerda da sentença uma estrutura hierárquica composta por categorias funcionais (FCs) com determinados traços semânticos em seus núcleos, e que o movimento de um determinado QP para uma dessas FCs é provocado pela necessidade desse elemento de checar seu traço semântico com o traço idêntico existente nessa determinada FC. Vejamos, então, essa estrutura em (03): 


\section{(03) Ref(erencial) P}

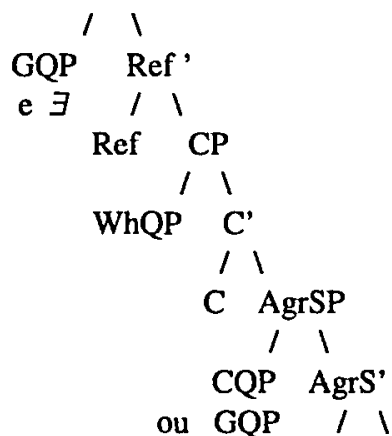

AgrS Dist(ributive) $P$

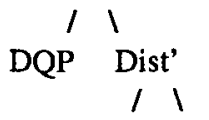

Dist ShareP

11

GQP Share'

e $\exists \quad / \quad$

Share NegP



Neg Agr IOP

11

CQP AgrlO'

ou GQP I I

AgrIO AgrDOP

11

CQP AgrDO'

ou GQP I I

AgrDO VP

11

$x$ evento VP

eAdv

Com base nessa tipologia, os autores identificam as seguintes funções lógicas e as posições em LF em que elas são satisfeitas:

1) WhQPs tomam escopo no Spec-CP, onde eles assumem sua força interrogativa pela da checagem de seu traço $[+\mathrm{Wh}]$ por meio da concordância do tipo especificador-núcleo com o operador interrogativo $Q$. 
POLLI, T. C. Aspectos da sintaxe de advérbios...

2) NQPs tomam escopo no Spec - NegP, onde seu traço [+Neg] é checado por meio da concordância do tipo especificador-núcleo com o núcleo (silencioso) Neg.

3) DQPs com each e every geralmente se movem para Spec-DistP, onde eles se submetem à concordância do tipo especificador-núcleo com o núcleo distributivo-universal Dist. Observam os autores que DQPs com every podem também ocupar outras posições em LF.

4) GQPs podem selecionar mais de uma posição em LF, resultando diferentes interpretações:

a) GQPs que são referencialmente independentes geralmente ocupam a posição Spec-RefP, onde cumprem a função de sujeito lógica da predicação, e são interpretados tendo escopo sobre outros elementos que atribuem escopo na sentença;

b) GQPs com um indefinido ou numeral sem artigo ocupam a posi ção Spec-ShareP. Estes são interpretados com "referência especí fica dependente". Enquanto GQPs específicos indefinidos podem ocupar ou Spec-ShareP ou Spec-RefP, GQPs definidos específicos devem normalmente ocupar Spec-RefP e são independentes em termos de escopo na oração em que se encontram.

c) GQPs indefinidos ou numerais sem artigo podem também ficar em suas posições de Caso, onde são interpretados não sendo específicos, como CQPs.

5) CQPs não podem geralmente ser interpretados de forma específica. Sendo assim, são interpretados em suas posições de Caso e tomam escopo insitu.

Resta-nos, então, exemplificar concretamente os QPs nessas posições da estrutura hierárquica proposta pelos autores. Vejamos algumas sentenças com esses constituintes:

(04) Every (or each) student read some texts.

(Todo [ou cada] aluno leu alguns textos).

Neste exemplo, o QP every student move-se em LF para uma posição que possui o mesmo traço semântico [+Dist] que ele, no caso a posição de Spec de DistP. Nesta posição esse DQP tem que descarregar suas propriedades distributivas sobre um outro constituinte, que no caso é some texts, um GQP que sobe justamente para a posição de Spec de ShareP sob o domínio de Spec de DistP. 
Neste caso, temos uma sentença ambígua, ou seja com duas interpretações possíveis: uma cujo significado é equivalente a "há apenas um químico e esse químico checou cada composto", e uma outra significando "cada composto foi checado por um químico diferente". O primeiro significado advém da possibilidade do GQP A chemist de ser movido em LF para Spec de RefP, tendo, conseqüentemente escopo sobre o DQP each compound em Spec de DistP. Nesse caso, a exigência de que DQPs têm que ter um domínio sobre o qual possam descarregar suas propriedades distributivas, expressa na teoria pela projeção obrigatória de ShareP como complemento de DistP, é satisfeita com o quantificador existencial de Spec, ShareP prendendo a variável sobre eventos contida no sintagma verbal. Já o segundo significado resulta de outra possibilidade: a do GQP A chemist de ser movido em LF para Spec de ShareP e ser ccomandado pelo DQP each compound em Spec, DistP (leitura de escopo distributivo invertido).

One student did not read each book.

(Um estudante não leu cada livro).

A negação sentencial é tratada como quantificação negativa sobre eventos. Esta propriedade semântica é derivada sintaticamente por meio da postulação de que o operador negativo ocupando a posição de núcleo da projeção funcional NegP prende o argumento evento gerado dentro de VP. Assim sendo, a interpretação da sentença é "para cada livro $x$, há um estudante y que não leu o livro x." Estando o argumento evento preso pelo operador negativo, esta é a única interpretação possível para a sentença, pois as propriedades distributivas do DQP each book em Spec, DistP precisam ser descarregadas no seu complemento que precisa, então, estar em Spec, Share P, já que o operador existencial nessa posição não prende o argumento evento de VP.

(07) John did not read every (*each) book. (John não leu todo (cada) livro).

Quando a variável representando o conjunto introduzido pela restrição do quantificador every é presa pelo operador negativo ou pelo operador de 
pergunta, every-DQPs não se movem para Spec, DistP. Isto explica por que eles podem ficar sob o escopo da negação, ao contrário de each-DQPs.

\section{Conclusão}

A partir das observações realizadas concernentes à tipologia de sintagmas quantificados e de suas diferentes propriedades de escopo, Beghelli e Stowell chegam às seguintes conclusões:

- Os sintagmas quantificados não podem ser entendidos como parte de um grupo homogêneo, e suas propriedades de escopo não podem ser idênticas.

- A negação é vista como quantificação negativa sobre eventos.

- GQPs movem-se em Forma Lógica para ShareP ou RefP, determinando o tipo de leitura (escopo).

- Alguns sintagmas quantificados apresentam uma distributividade forte: each e every, sendo que este último é subespecificado com relação a essa propriedade, fator que o possibilita ocupar outras posições além de Spec-DistP emLF.

- Alguns sintagmas quantificados apresentam uma distributividade opcional: GQPs indefinidos e definidos plurais.

\section{A proposta de Costa (2000) sobre os advérbios em adjunção a XP}

\section{Apresentação}

Costa, contrariamente a Cinque (1999) argumenta que, pelo menos em português europeu (PE), os advérbios não ocupam a posição de especificador de determinadas categorias funcionais e que estas não são universais. Seus argumentos são sustentados por evidências empíricas nesse idioma, tais como:

1. A ocorrência de advérbios na sentença é dependente da existência de núcleos lexicais, o que não é verdadeiro para especificadores.

2. Os advérbios comportam-se como outros adjuntos em construções clivadas. 
POLLI, T. C. Aspectos da sintaxe de advérbios...

A seguir, apresentaremos de forma sintética as evidências detectadas pelo autor para cada um dos argumentos acima.

\section{A ocorrência de advérbios como dependente da existência de núcleos lexicais}

Conforme o previsto em Cinque (1999), muitos advérbios podem aparecer entre os núcleos verbais de uma sentença. Isto está ilustrado em (08) abaixo: (08) [ O Paulo [ cuidadosamente tinha [ simpaticamente lido ${ }_{1}$ [ bem $t_{1}$ o livro à avó.]]]] $\begin{array}{llll}\text { XP XP } & \text { XP }\end{array}$

Em (08), explica o autor, um advérbio orientado para o sujeito ocorre entre o sujeito e o verbo auxiliar, um advérbio de modo ocorre entre o auxiliar e a forma participial do verbo principal, e um advérbio de modo baixo ocorre entre a forma participial do verbo principal e de seu complemento. Estas posições estão previstas em Cinque (1990), pois este autor advoga que, para cada núcleo verbal numa categoria funcional específica, existe uma posição de especificador que pode ser ocupada por um advérbio. Dessa forma, se os advérbios são especificadores de categorias funcionais que são projetadas universalmente, eles podem aparecer nas sentenças independentemente da visibilidade dos núcleos dessas categorias. Em outras palavras, observa o autor, a previsão é que os especificadores podem existir independentemente da realização [visível] de seus núcleos.

Apesar de muito bem elaboradas as argumentações de Cinque, Costa (2000) detecta que a possibilidade de se acrescentar advérbios nas sentenças não está sempre disponível. Em alguns contextos, a ocorrência de advérbios parece ser dependente da existência de um núcleo lexical. Este fato pode ser facilmente observado quando a sentença (08) é comparada a (09). A diferença entre elas é que (09), contrariamente a (08), não possui um verbo auxiliar. Se os advérbios que ocorrem em (08) são especificadores de categorias ocupadas por núcleos verbais, a previsão feita é que eles aparecem na sentença independentemente da realização dos núcleos das FCs. Contudo, esta previsão não é confirmada, como a agramaticalidade da sentença (09) nos mostra:

* O Paulo leu cuidadosamente simpaticamente bem o livro à avó. 
Explica Costa que a única possibilidade desses advérbios coocorrerem na sentença com apenas um núcleo verbal é pela da coordenação, como em (10):

O Paulo leu bem, cuidadosa(mente) e simpaticamente o livro à avó.

O fato de que os advérbios devem ser coordenados em (10) pode ser interpretado como evidência a favor da análise de acordo com a qual eles são adjuntos. Se existe um único núcleo verbal, existe apenas uma posição de adjunção. É por isso, então, que, nesse caso, múltiplos advérbios são forçados a serem coordenados.

Além disso, salienta o autor, a agramaticalidade da sentença (09) pode ser interpretada como uma evidência a favor da não universalidade das categorias funcionais, conforme Thráinsson (1996). Se os advérbios não podem aparecer na sentença é porque as categorias funcionais que os abrigam não foram projetadas.

\section{O comportamento dos advérbios semelhante a outros adjuntos em construções clivadas}

Costa advoga que um outro argumento a favor da visão tradicional de acordo com a qual os advérbios são adjuntos advém do comportamento destes elementos em construções clivadas. Como nas outras línguas, qualquer XP pode ser clivado em português. Em (11), o autor apresenta-nos exemplos de clivagens envolvendo os seguintes constituintes: DP, VP, PP, AP, CP e AdvP :
a) Foi $l_{D P}$ o Paulo] que leu o livro.
b) Foi $\left[_{\mathrm{vp}}\right.$ ler o livro] o que o Paulo fez.
c) Foi $\left[_{P p}\right.$ à praia] que o Paulo foi.
d) $E\left[_{A P}\right.$ alto] que o Paulo acha aquele monte.
e) Foi $\left[_{\mathrm{CP}}\right.$ que ia á praia] que o Paulo disse.
f) Foi $\left[_{\text {AdvP }}\right.$ ontem] que o Paulo leu o livro.

Se considerarmos as clivagens com DPs, observa o autor, um contraste sutil de gramaticalidade surge entre clivagens em que o elemento inicial do DP 
clivado é um adjetivo, e clivagens em que o elemento inicial do DP clivado é um substantivo ou um determinante. Isto pode ser observado em (12):

a) ?/* Foram pobres homens que o João matou.

b) Foram homens pobres que o João matou.

Contudo, se os DPs em (13) começam com um determinante, a clivagem é mais aceita:

a) Foram os pobres homens que o João matou.

b) Foram aquelas horriveis palavras que o Paulo lhe disse.

Observa o autor que, por alguma razão, o elemento inicial de um XP clivado não pode ser um adjunto dentro daquele XP. Embora Costa não tenha explicação para esta restrição, advoga que é possível usá-la para questionar o estatuto dos advérbios. Se eles são adjuntos, está previsto que eles não devem aparecer na posição inicial quando o constituinte que o contém está clivado. Tal previsão é sustentada empiricamente. Os VPs podem ser clivados mesmo se eles contêm advérbios; no entanto, estes não podem aparecer no início do constituinte clivado, como mostram os exemplos abaixo:

(14) a) Foi [dar o livro à Maria simpaticamente] o que o João fez.

b) Foi [dar simpaticamente o livro à Maria] que o João fez.

c) Foi [dar o livro simpaticamente à Maria] que o João fez.

d) * Foi [ontem ler o livro] o que o João fez.

e) * Foi [simpaticamente dar o livro à Maria] o que o João fez.

Costa convida-nos a observar que os elementos clivados podem, no entanto, iniciar com um especificador. Isto está ilustrado em (15). Em (15 a), temos a clivagem do sujeito sentencial de uma oração pequena (SC), a qual inicia com um sujeito em Spec, IP no PE. Em (15 b), ocorre a clivagem do complemento do verbo perguntar. Seu elemento inicial é um sintagma-QU em Spec, CP. Vejamos: 
a) Foi [o João ir à praia] que a Maria achou estranho.

b) Foi [quem tinha visto] o que a Maria perguntou ao Pedro.

Salienta ainda o autor que é importante notar que esta restrição não tem nada a ver com a força predicativa de elementos clivados. Os APs predicativos bem como os sintagmas adverbiais podem ser clivados, resultando em sentenças gramaticais, como em (16) e (17):

(16) É [cansado] que o Paulo está.

(17) Foi [ontem] que o Paulo leu o livro.

Dessa forma, observa o autor, o fato de que os elementos clivados podem ser iniciais em Spec, XP, que DPs clivados não podem iniciar com um adjunto, e que os advérbios não podem ser o elemento inicial de um constituinte clivado reforçam a hipótese de que os advérbios são adjuntos. Se fossem especificadores, deveriam poder exibir um comportamento semelhante ao dos especificadores e diferente ao dos adjuntos.

\section{Conclusão}

A partir das observações realizadas concernentes a advérbios e projeções funcionais, a diferenças entre advérbios e especificadores, e a restrições em construções com XPs clivados, Costa chega às seguintes conclusões:

- Os advérbio comportam-se diferentemente dos especificadores.

- Se as projeções funcionais fossem sempre projetadas, independentemente da realização lexical de seus núcleos, os locais de adjunção deveriam estar sempre disponíveis.

- Se a estrutura funcional for projetada apenas quando for necessária para a lexicalização dos núcleos verbais, a adjunção de advérbios fica dependente da realização desses núcleos.

- As clivagens são sensíveis ao estatuto do elemento inicial: este não pode ser um adjunto.

- Como outros adjuntos e diferentemente de especificadores, os advérbios não podem ocorrer no início de um constituinte clivado. Se os advérbios 
fossem especificadores, eles deveriam poder aparecer na posição inicial de um constituinte clivado.

\section{Análises}

\section{Introdução}

Na seção anterior foram apresentadas justificativas apontadas por Costa (2000) para adotarmos a hipótese tradicional de que os advérbios, pelo menos os não-subcategorizados, são adjuntos. Sendo assim, são gerados em adjunção à categoria XP que eles modificam. Apresentamos, também, o motivo de adotarmos o modelo de atribuição de escopo em LF proposto por Beghelli e Stowell (1997). Resta-nos, então, aplicarmos as teorias dos respectivos autores a sentenças do PB como as $(01$ a,b) e (02 a,b) da Introdução deste artigo, para tentarmos descrever o fato de que os advérbios ${ }^{2}$ celerativos, ora possuem a capacidade de quantificarem os eventos distribuídos no VP, ora quantificam os eventos coletivamente, sem distribuir sua predicação sobre cada um deles, dependendo da posição em que se encontram na sentença e de seu escopo em LF.

\section{Aplicação das Teorias}

Concentremo-nos nas sentenças com advérbios de aspecto celerativo a seguir:

a) Rapidamente os passageiros embarcaram no trem.

b) Os passageiros rapidamente embarcaram no trem.

c) Os passageiros embarcaram rapidamente no trem.

d) Os passageiros embarcaram no trem rapidamente.

2 Concentramo-nos apenas em advérbios em -mente, em virtude da complexidade do assunto e da necessidade de restringirmos o campo de abordagem deste artigo, por razōes de tempo e de espaço. 
Sem considerarmos pausas entre o advérbio e os outros constituintes das sentenças, já que poderiam ser marcadas pelo uso da vírgula na escrita e indicar deslocamento à esquerda do advérbio, fator que camuflaria uma das interpretações que queremos descrever, vejamos qual é a leitura que cada uma tende a desempenhar e por quê.

Quanto às sentenças (18 a e b), observamos que o advérbio rapidamente em posição inicial ou em posição auxiliar (entre sujeito e verbo principal) não consegue distribuir sua predicação sobre mais de um evento de VP, ou seja, a interpretação das sentenças é de que há apenas um evento coletivo e que, conseqüentemente, o tempo decorrido até o momento em que todos os passageiros encontram-se dentro do trem não foi longo. Vejamos como podemos explicar este fato pela da descrição gramatical proposta por Costa (2000) e Beghelli e Stowell (1997).

Adotando a proposta de Beghelli e Stowell, a qual advoga que a interpretação de sintagmas quantificados dá-se pelo de seu alçamento em LF para determinadas projeções funcionais existentes na periferia esquerda das sentenças, podemos utilizar as projeções que desempenham o processo distributivo presentes nessa estrutura, para explicarmos porque os advérbios celerativos podem ou não distribuir sua predicação aos eventos do VP. Conforme advogam os autores, os advérbios que qualificam o argumento evento são gerados internamente ao VP, na posição do argumento evento. Supomos que o advérbio, apesar de conseguir predicar sobre o argumento evento do VP, precisa mover-se em LF para uma projeção funcional específica (DistP) em que a predicação distributiva seja realizada e provavelmente também para checar seu possível traço semântico [+Dist]. Por ser o advérbio um adjunto (conforme argumenta Costa (2000) que os advérbios são adjuntos e não especificadores), não entra na posição de Spec da projeção DistP, pois esta está reservada para DQPs. A representação estrutural das sentenças (18 c e d) em (19) ilustra esta situação.

Supomos também que o traço semântico do advérbio (talvez [+Dist]) pode percolar ${ }^{3}$ através de DistP e alcançar o núcleo desta projeção para realizar a checagem do traço relevante e ativar esse núcleo. Consequientemente, o complemento de Dist é ativado também. Embora o GPQ definido os passageiros não possa se mover para Spec-ShareP, pois já se moveu para uma posição (Spec-RefP) em que passou a ser o sujeito da predicação antes de spell-out, a variável de evento do VP presa pelo operador existencial em ShareP é suficiente para funcionar como domínio de distribuição para os advérbios celerativos, pois, na verdade, é o alvo da

3 A idéia de percolação de traços do advérbio para o interior da projeção máxima que o domina não é nova: Travis (1988) defende esta hipótese. 
predicação do advérbio, gerando a interpretação distributiva em que o advérbio distribui sua predicação a cada um dos eventos do VP realizados por sujeitos distintos (cada passageiro $x$ com seu ato de embarcar $y$ da mesma forma $z$ ).

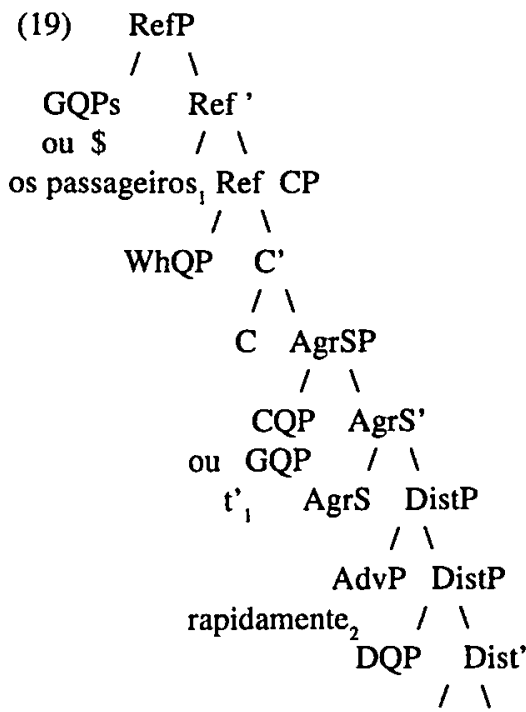

Dist ShareP

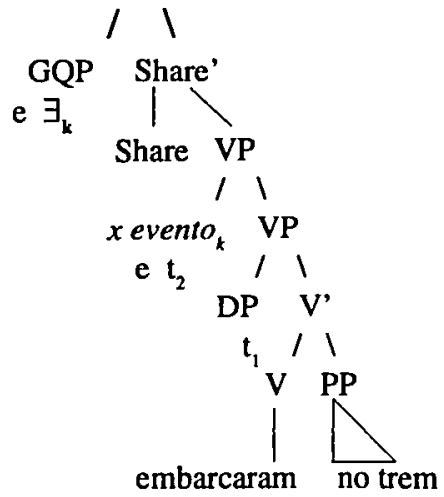

O mesmo pode ser observado nessas sentenças em suas formas negativas, ilustradas em (20) e (21), respectivamente: 
(20) Os passageiros não embarcaram rapidamente no trem.

(21) Os passageiros não embarcaram no trem rapidamente.

Apesar de a variável de evento do VP ser presa pelo operador negativo de NegP, já que a negação é vista como quantificação negativa sobre eventos, a negação não impede o movimento do advérbio rapidamente para uma posição adjunta a DistP, pois este tem seu traço semântico a ser checado e precisa adquirir escopo sobre a negação, para distribuir sua predicação sobre ela. Supomos, seguindo Travis (1988), que o escopo dos advérbios é atribuído por meio da percolação de traços, e que estes são fortes o suficiente para passarem por ShareP , alcançarem NegP e atingir a variável de evento que está presa ao operador negativo. Sendo este processo viável, não é de se estranhar que nas sentenças negativas (20) e (21) acima, manifesta-se a interpretação semelhante a "cada passageiro $x$ não teve o seu evento de embarcar $y$ da mesma forma $z$ ", pois o advérvio distribui sua predicação sobre a negação e esta, por seu turno, predica sobre a variável de evento. A representação estrutural destas sentenças está ilustrada em (22) abaixo:

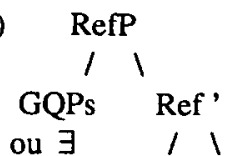

os passageiros, $_{1}$ Ref $\mathrm{CP}$

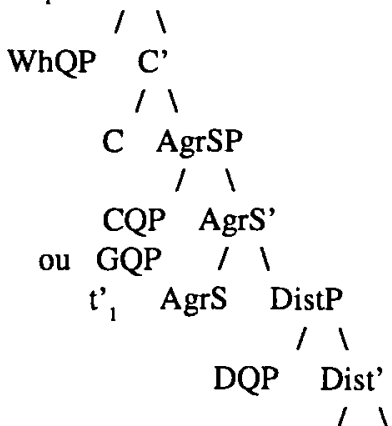

Dist ShareP

$\begin{array}{cc}/ & \text { I } \\ \text { GQP } & \text { Share' } \\ \text { e } \exists \quad / & / \\ \text { Share } & \text { NegP } \\ & / \\ \text { NQP Neg' }\end{array}$




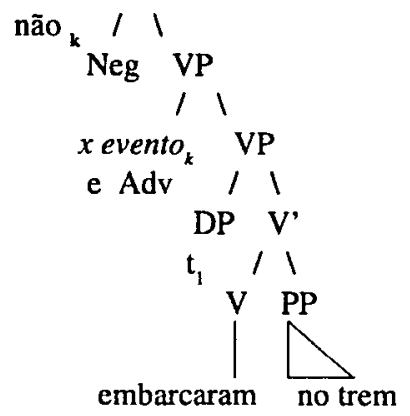

Como vimos, o fato de que o advérbio se move para uma posição adjunta a DistP justifica-se pela necessidade desse elemento de checar seu traço [+Dist] com o operador distributivo dessa projeção. Isso ocorre mesmo diante da negação, pois o fato de o operador existencial em Spec-ShareP não prender a variável de evento não impede a distribuição da predicação adverbial, uma vez que esta precisa ocorrer sobre a negação, onde a variável de evento está presa, ou seja, em Spec-NegP.

Observamos, também, que a ausência do advérbio celerativo numa posição pós-verbal na sentença deixa a interpretação dos eventos como sendo eventos individuais, com ou sem negação, como ilustra a sentença (23):

(23) Os passageiros (não) embarcaram no trem.

fator que reforça a hipótese de que a presença desses advérbios na sentença é que pode ou não transformar eventos individuais num evento coletivo.

Já no caso das sentenças (18 a e b), repetidas aqui como (24 a e b):

a) Rapidamente os passageiros embarcaram no trem.

b) Os passageiros rapidamente embarcaram no trem.

nas quais o advérbio se encontra ou na posição inicial ou na posição auxiliar, parece não ocorrer a distribuição da predicação do advérbio sobre os eventos. Neste caso, supomos que o advérbio é gerado fora do VP, não tendo escopo sobre a variável de evento lá existente e, consequientemente, com um traço semântico relevante (talvez [-Dist]). Dessa forma, o advérbio não se move em adjunção a DistP em LF para checar o traço distributivo. Também, como resultado, o núcleo Dist e seu complemento ShareP não são ativados. Vejamos a descrição desses fatos 
estruturalmente ilustrada em (25). Desta vez, marcamos em negrito as partes da estrutura que não são projetadas:

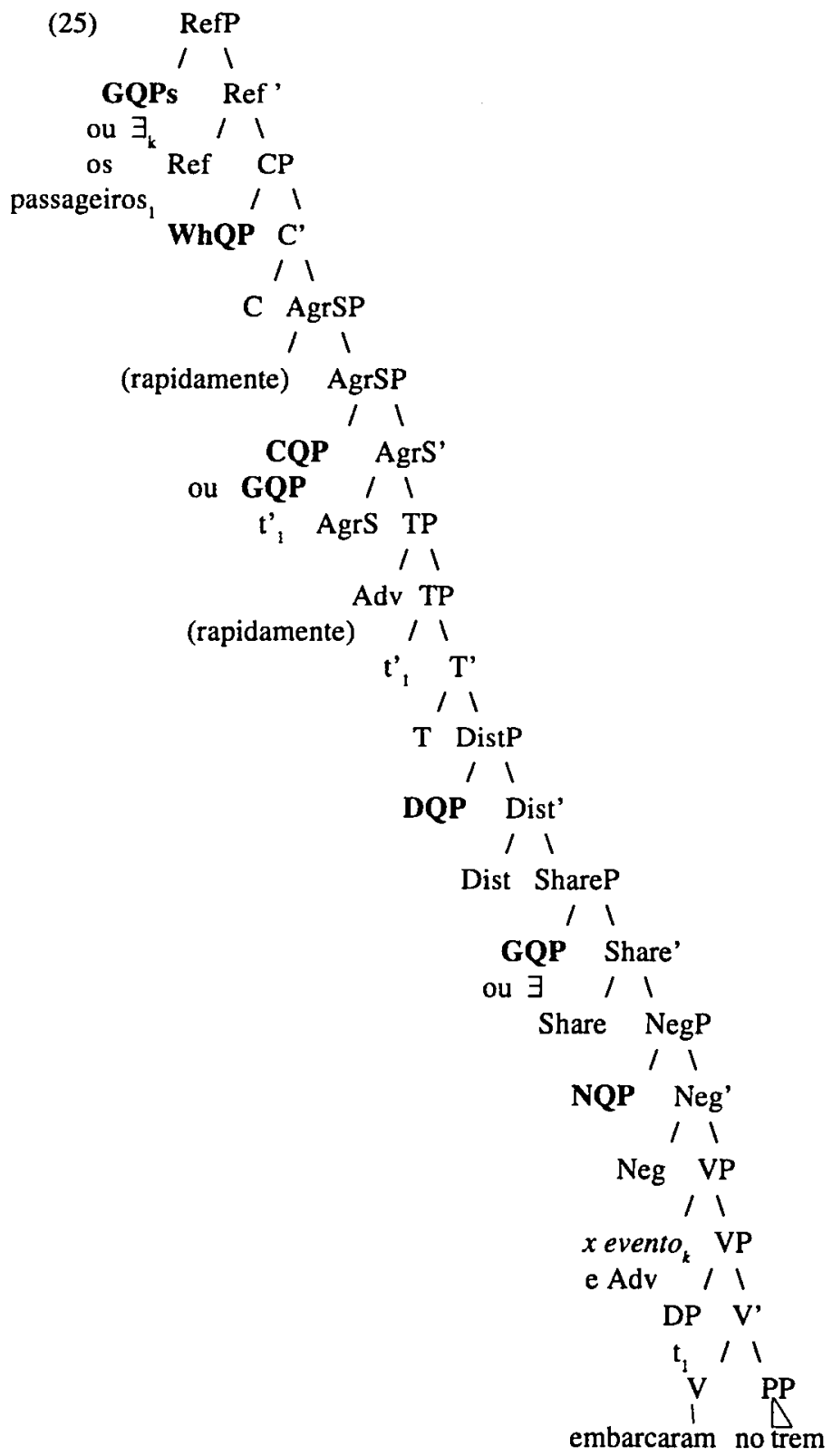


Na estrutura acima, a variável do argumento evento é presa pelo operador existencial / genérico em RefP, fora do escopo do advérbio que, por não possuir o traço [+Dist], uma vez que foi gerado fora do VP, não precisa ser movido em LF para checar esse traço semântico. Dessa forma, o advérbio celerativo, por não distribuir sua predicação sobre os eventos do VP, já que foi gerado fora dele, faz com que esses eventos sejam interpretados coletivamente: tendo apenas um evento de embarcar, temos também apenas um momento anterior e um posterior a este evento, sendo que o espaço de tempo percorrido para se chegar de um momento ao outro é rápido. É este significado que as sentenças em (24) veiculam.

Cabe-nos observar ainda que aos advérbios celerativos podem ser gerado fora do VP em pelo menos duas posições distintas, em adjunção a AgrSP ou a TP, dependendo de possuírem ou não um traço semântico (talvez [+Dist]). Porém, o fator de seu licenciamento numa posição ou noutra foge do escopo deste artigo, o qual tem como objetivo apenas mostrar que advérbios celerativos em -mente podem fazer com que os eventos do VP sejam interpretados coletivamente ou não, dependendo da posição em que são gerados na estrutura frásica, bastando esta posição ser fora ou dentro do VP.

Voltemo-nos, agora, para as sentenças ( $24 \mathrm{a} \mathrm{e} \mathrm{b}$ ) em suas formas negativas, reapresentadas abaixo em (26) e (27), respectivamente, para tentarmos explicar estruturalmente o porquê de elas serem agramaticais. Salientamos o fato de que não estamos lidando com construções marcadas:

* Rapidamente os passageiros não embarcaram no trem.

* Os passageiros rapidamente não embarcaram no trem.

Como foi visto anteriormente na análise destas mesmas sentenças em suas formas afirmativas, a leitura distributiva da predicação adverbial sobre eventos não é possível porque os advérbios são gerados numa posição fora do VP, por não possuírem um possível traço [+Dist] para ativar os núcleos das projeções DistP e ShareP. Além deste mesmo fato, as sentenças (26) e (27) possuem um operador negativo que acaba prendendo a variável de evento do VP. Tendo em mente que o advérbio de negação, conforme Beghelli e Stowell (1997), é gerado dentro do VP no argumento evento e movido em LF, dependendo do idioma, para Spec-NegP, em virtude de sua necessidade de checagem do traço [+Neg], e que, conforme nossa proposta, os advérbios celerativos gerados fora do VP não precisam se mover para checar traço nenhum, não há posição disponível na estrutura para a negação ficar acima dos advérbios, pois AgrSP e TP estão acima de NegP. É por isso, então, que 
POLLI, T. C. Aspectos da sintaxe de advérbios...

as sentenças (26) e (27) são agramaticais. Sua representação estrutural está ilustrada em (28):

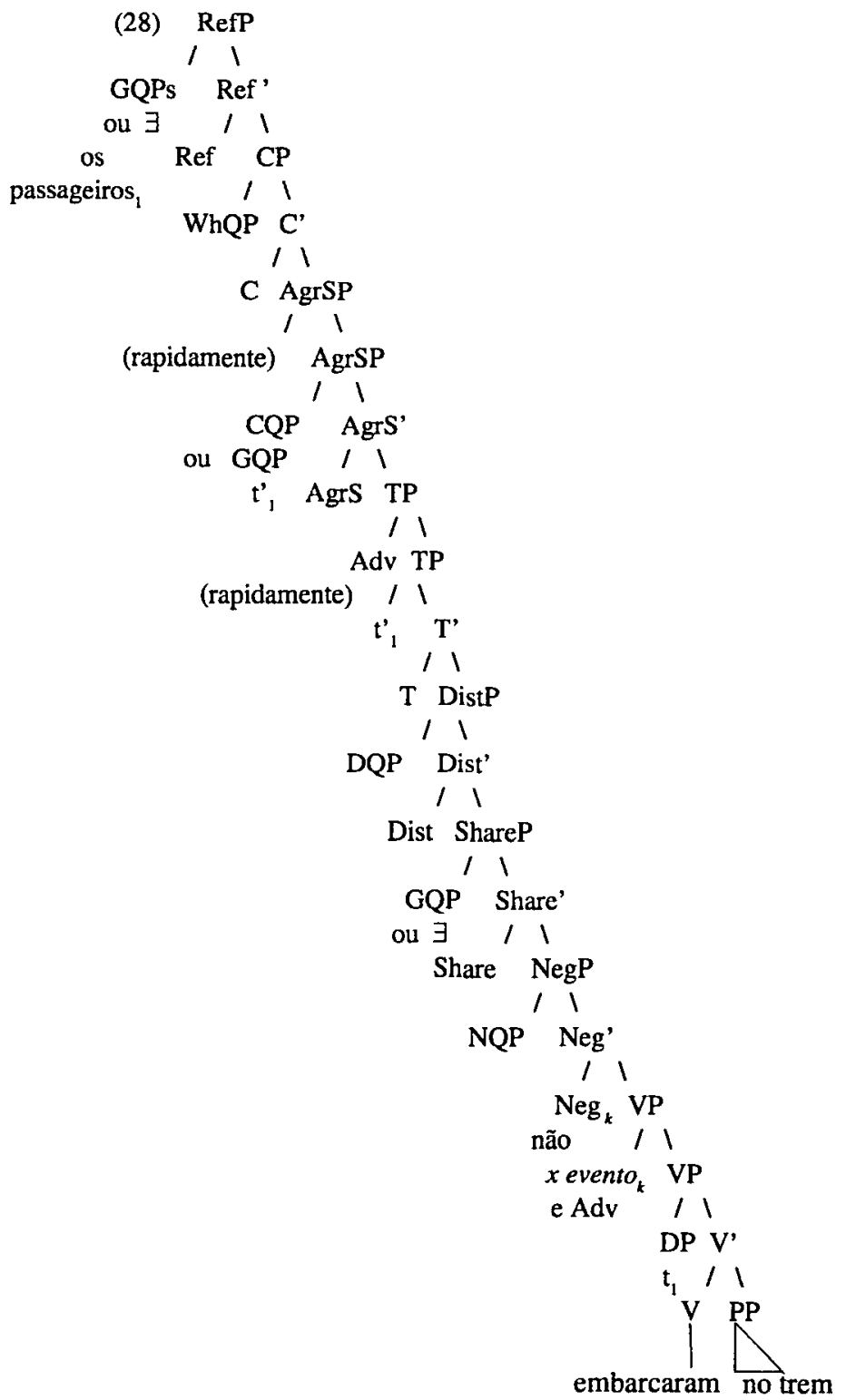




\section{Conclusão}

Tendo em vista o fato de que, nas sentenças (18 c e d), (20) e (21), o advérbio celerativo consegue distribuir sua predicação sobre os eventos de VP, tanto em frases afirmativas como em negativas, propomos que ele seja gerado internamente a VP para já estabelecer sua natureza predicativa com o argumento evento lá existente, e com um traço semântico [+Dist] que precisa ser checado em LF para efetivar a distribuição de sua predicação sobre a variável evento de VP. Dessa forma, quando o advérbio celerativo é gerado fora de VP, propomos que ele não apresenta o traço semântico [+Dist] e, em virtude deste fato, que ele não predica sobre a variável de evento, mas sim sobre alguma outra variável talvez relacionada ao tempo verbal situada em TP ou em AgrSP, fazendo com que os eventos de VP sejam interpretados coletivamente.

\section{Considerações finais}

Os estudos adverbiais de Costa apresentados neste artigo, de fato, nos levam a refletir sobre a suposta necessidade da existência de todas as categorias funcionais numa simples sentença bem como sobre sua suposta posição de geração em Spec-XP. Observando-se a semelhança do comportamento dos advérbios não-subcategorizados por um predicador ao comportamento de adjuntos, não apenas rompemos com a hipótese de que eles sejam especificadores, mas também os distanciamos dos processos de licenciamento de predicados e argumentos, pois não são nem uma coisa nem outra: são adjuntos. Já que possuem uma condição de licenciamento diferenciada, é natural, também, que possuam um processo de atribuição de escopo também diferenciado: talvez através da percolação de seus traços, e não através de uma relação de concordância entre Spec e Núcleo.

As projeções funcionais na periferia esquerda da sentença propostas por Stowell (1995) como posições de pouso em LF para diferentes sintagmas quantificados, por possuírem propriedades diferentes, parecem poder serem utilizadas também pelos advérbios celerativos, pelo menos a projeção DistP, supondo-se que eles possuam uma propriedade distributiva que precisa ser checada e descarregada. Estabelecendo relações de escopo entre esses advérbios e a variável do argumento evento de VP, detectamos uma alteração na interpretação dos eventos: se a variável de evento fica sob o escopo do advérbio celerativo, a interpretação individual dos eventos é mantida; por outro lado, 
POLLI, T. C. Aspectos da sintaxe de advérbios...

se a variável de evento não fica sob o escopo desse advérbio, a interpretação coletiva dos eventos advém.

De fato, não está muito claro exatamente como esse processo de alteração da interpretação dos eventos individuais para uma interpretação coletiva se realiza. Simplesmente tentamos mostrar que as propriedades semânticas e de escopo dos advérbios celerativos exercem um papel fundamental nesse processo, deixando, em aberto a novas pesquisas, a interação desse fenômeno com o movimento do verbo e com a problemática de não existir uma posição para a negação acima de TP e AgrSP.

\section{RESUMO}

Este artigo concentra-se na relação existente entre os advérbios celerativos em -mente do $\mathrm{PB}$ e as propriedades distributivas de sintagmas quantificados distributivos universais. Primeiramente mostramos que os advérbios que indicam velocidade, dependendo da posição em que se encontram na sentença, podem modificar a interpretação de eventos individuais para um único evento, um evento coletivo. Baseando-nos em propostas de Beghelli (1995) e de Beghelli e Stowell (1997) sobre a interpretação em Forma Lógica de sintagmas quantificados, demonstramos a possibilidade de esses advérbios serem subespecificados quanto a um traço semântico [Dist]. Quando possuem o traço [+Dist] são gerados internamente a VPe movem-se em Forma Lógica para checarem este traço em DistP e realizarem a distribuição de sua predicação sobre a variável de evento presa em ShareP, mantendo a interpretação individual dos eventos, em virtude da distribuição da predicação adverbial sobre eles. Contudo, quando os advérbios celerativos não possuem o traço [+Dist], são gerados fora do VP e, em virtude de não predicarem sobre a variável de evento de $V P$, provocam a mudança da interpretação individual dos eventos para uma interpretação coletiva. Sentenças negativas também foram estudadas e nelas estes advérbios apresentaram a mesma propriedade. Consideramos os advérbios como sendo adjuntos, conforme os argumentos apresentados na proposta de Costa (2000) para os advérbios do português europeu, e seguimos a teoria sobre Sintaxe Adverbial de Travis (1988) para demonstrarmos o processo de percolação de traços adotado para a atribuição do escopo dos advérbios.

Palavras-chave: advérbios, distribuidade, predicação. 


\section{ABSTRACT}

This paper concentrates on the relation between celerative -ment adverbs (of Brazilian Portuguese) and the distributive proprieties of universal distributive quantified phrases. Firstly we show that adverbs that express velocity, depending on the position they appear in a sentence, can change the interpretation of its events: the atomic event interpretation of a sentence is turned into a collective one or vice-versa. Adopting proposals by Beghelli (1995) and Beghelli and Stowell (1997) about the interpretation of quantified phrases in Logical Form, we show the possibility for such adverbs of being underspecified in relation to a semantic feature [Dist]. We claim that, whenever they have the feature [+Dist], they are generated inside VP and move, in Logical Form, in order to check that feature against DistP and to distribute their predication over an event variable bound in ShareP, keeping the interpretation of events individually, due to the distribution of the adverbial predication over them. However, whenever a celerative adverb does not possess the feature [+Dist], it is generated outside the VP and, since it does not predicate over the event variable in VP, it provokes a change in the event interpretation: the interpretation of the event as atoms turns into a collective one. Negative sentences have also been taken into consideration and, inside them, celerative adverbs present the very same proprieties as if they were outside them. In this work, adverbs are considered adjuncts, in accordance with the claims presented by Costa's (2000) proposal for European adverbs. The theory on Adverbial Syntax adopted here is the one developed by Travis (1988), which is used in order to demonstrate the process of feature percolation for the scopal assignment of adverbs.

Key-words: adverbs, distributivity, predication.

\section{REFERÊNCIAS}

BEGHELLI, F. The phrase structure of quantifier scope. Los Angeles, 1995. Dissertation (Ph.D) - University of California.

BEGHELLI, F; STOWELL, T. Distributivity and Negation. The syntax of EACH and EVERY. In: SZABOLCSI, A. (Ed.). Ways of scope taking. Dordrecht: Kluwer, 1997. p. 71-109.

CINQUE, G. Adverbs and Functional Heads. A cross-linguistic perspective. Oxford: Universiy Press, 1999.

COSTA, J. Adverbs as Adjuncts to Non-Universal Functional Categories evidence. From Portuguese. ZAS Papers in Linguistics, 2000. No prelo. 
POLLI, T. C. Aspectos da sintaxe de advérbios...

TRAVIS, L. The Syntax of Adverbs. Papers in Syntax, McGrill University, p. 280-310, 1988. 